\title{
河道平面形状の形成における河床・河岸の 変動特性の相互関係について \\ MUTUAL EFFECTS OF BED AND BANK DEFORMATION IN CHANNEL PLANE FORMATION
}

\author{
清水康行 ${ }^{1}$ \\ Yasuyuki SHIMIZU \\ ${ }^{1}$ 正会員 工博 北海道大学大学院工学研究科助教授 (
}

\begin{abstract}
A numerical model is developed to simulate the formation of braided stream, in which bank erosion and bed deformation are calculated simultaneously. Flow field, bed deformation, bank erosion and channel geometry are calculated numerically with a general coordinate system, which can be applied to any shape of channel geometry during the deformation of channel geometry due to the bank erosion. Calculation is started with a narrow straight channel with flat bed, and in tern the development of alternate bar, channel meandering, appearance of mid channel bar, and finally, a braided channel geometry is simulated. Computational results are favorably compared with experimental. The mutual effect of bank and bed defoemation to the channel plane geometry is disscused.
\end{abstract}

Key words: bank erosion, bed deformation, numerical model, CIP numerical scheme.

\section{1. はじめに}

河川の河床・河道形状を定量的に予測することは河川 工学上重要な課題である．特に近年は河川環境や生態 系に配慮した河川改修に対する社会的なニーズも高く， 従来のようにコンクリートブロックで保護された河岸 より出来るだけ自然状態に近い河岸の河川が求められ る傾向が多いため, 河岸の侵食も考慮した河道設計が重 要である. 従来の河床変動の計算モデルは, そのほとん どが, 河岸が固定された条件によるものである.しかし ながら自然河岸の河川の場合, 河床の変化上河岸の変化 は相互に密接に関連していることは容易に推定される. 長田ら $\left.{ }^{1,2}\right)$ や清水ら ${ }^{3)}$ は河床変動モデルと河岸侵食モ デルを組み合わせて, 緩やかに蛇行する砂質河岸・河床 材料を有する河道の河床・平面形状の変化を追跡する モデルの提案を行っているが, 本研究では直線河道を初 期条件として河岸侵食と河床変動が同時に進行する条 件での河岸の耐侵食強度と河道平面形状の相互関係に ついて検討を行う. 河道の平面形状は時間とともに任 意に変化するので, 移動一般座標を用いた流れと河床変 動の基礎式を用いる. 河岸侵食や河床変動の状況によっ ては流れが局所的に急激に変化するため, 流れの計算法 には急変部の計算も可能な CIP 法 ${ }^{4)}$ を用いる. 計算も デルの検証は Bertoldi ら ${ }^{5)}$ の実験結果との比較により
行う. 検証されたモデルを用いて, 河岸の耐侵食強度を 様々に変化させた場合の河道の変形状況を追跡する数 值実験を行い, 計算結果を用いて河岸の耐侵食強度と河 床変動の相互作用による河道平面形状の変化について 考察を行う。

\section{2. 流れと河床変動の基礎式}

境界が移動する場合の一般座標 2 次元流れの基䃈式と して, 以下の式を用いる.

$$
\begin{gathered}
\frac{\partial}{\partial \tau}\left(\frac{h}{J}\right)+\frac{\partial}{\partial \xi}\left[\left(\xi_{t}+u^{\xi}\right) \frac{h}{J}\right]+ \\
\frac{\partial}{\partial \eta}\left[\left(\eta_{t}+u^{\eta}\right) \frac{h}{J}\right]=0 \\
\frac{\partial u^{\xi}}{\partial \tau}+\left(\xi_{t}+u^{\xi}\right) \frac{\partial u^{\xi}}{\partial \xi}+\left(\eta_{t}+u^{\eta}\right) \frac{\partial u^{\xi}}{\partial \eta} \\
+\alpha_{1} u^{\xi} u^{\xi}+\alpha_{2} u^{\xi} u^{\eta}+\alpha_{3} u^{\eta} u^{\eta}-D_{\xi} \\
=-g\left[\left(\xi_{x}{ }^{2}+\xi_{y}{ }^{2}\right) \frac{\partial H}{\partial \xi}\left(\xi_{x} \eta_{x}+\xi_{y} \eta_{y}\right) \frac{\partial H}{\partial \eta}\right] \\
-\frac{C_{d} u^{\xi}}{h J} \sqrt{\left(\eta_{y} u^{\xi}-\xi_{y} u^{\eta}\right)^{2}+\left(-\eta_{x} u^{\xi}-\xi_{x} u^{\eta}\right)^{2}}
\end{gathered}
$$


(a)

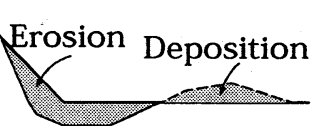

(b)

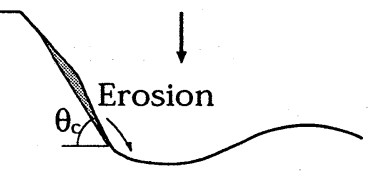

(c)

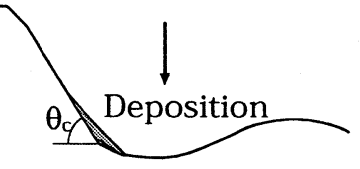

図-1 河岸侵食の計算法模式図

$$
\begin{gathered}
\frac{\partial u^{\eta}}{\partial \tau}+\left(\xi_{t}+u^{\xi}\right) \frac{\partial u^{\eta}}{\partial \xi}+\left(\eta_{t}+u^{\eta}\right) \frac{\partial u^{\eta}}{\partial \eta} \\
+\alpha_{4} u^{\xi} u^{\xi}+\alpha_{5} u^{\xi} u^{\eta}+\alpha_{6} u^{\eta} u^{\eta}-D_{\eta} \\
=-g\left[\left(\eta_{x}{ }^{2}+\eta_{y}{ }^{2}\right) \frac{\partial H}{\partial \eta}\left(\xi_{x} \eta_{x}+\xi_{y} \eta_{y}\right) \frac{\partial H}{\partial \xi}\right] \\
-\frac{C_{d} u^{\eta}}{h J} \sqrt{\left(\eta_{y} u^{\xi}-\xi_{y} u^{\eta}\right)^{2}+\left(-\eta_{x} u^{\xi}-\xi_{x} u^{\eta}\right)^{2}}
\end{gathered}
$$

ここで, $\xi, \eta$ は一般座標上での平面座標軸, $\tau$ は一般座標 上での時間軸, $h$ は水深, $H$ は水位, $u^{\xi}, u^{\eta}$ は $\xi, \eta$ 方向の 流速の反変成分, $C_{d}$ は河床の摩擦係数, $J$ は座標変換の ヤコビアン, $D_{\xi}, D_{\eta}$ は拡散項で, Shimizu \& Itakura ${ }^{6)}$ によるものを用いる. また, 他の係数は以下の諸式で与 えられる。

$$
\begin{gathered}
\tau_{t}=\frac{\partial \tau}{\partial t} \quad \tau_{x}=\frac{\partial \tau}{\partial x} \quad \tau_{y}=\frac{\partial \tau}{\partial y} \\
\xi_{t}=\frac{\partial \xi}{\partial t} \quad \xi_{x}=\frac{\partial \xi}{\partial x} \quad \xi_{y}=\frac{\partial \xi}{\partial y} \\
\eta_{t}=\frac{\partial \eta}{\partial t} \quad \eta_{x}=\frac{\partial \eta}{\partial x} \quad \eta_{y}=\frac{\partial \eta}{\partial y} \\
\alpha_{1}=\xi_{x} \frac{\partial^{2} x}{\partial \xi^{2}}+\xi_{y} \frac{\partial^{2} y}{\partial \xi^{2}} \\
\alpha_{2}=2\left(\xi_{x} \frac{\partial^{2} x}{\partial \xi \partial \eta}+\xi_{y} \frac{\partial^{2} y}{\partial \xi \partial \eta}\right) \\
\alpha_{3}=\xi_{x} \frac{\partial^{2} x}{\partial \eta^{2}}+\xi_{y} \frac{\partial^{2} y}{\partial \eta^{2}} \\
\alpha_{4}=\eta_{x} \frac{\partial^{2} x}{\partial \xi^{2}}+\eta_{y} \frac{\partial^{2} y}{\partial \xi^{2}} \\
\alpha_{5}=2\left(\eta_{x} \frac{\partial^{2} x}{\partial \xi \partial \eta}+\eta_{y} \frac{\partial^{2} y}{\partial \xi \partial \eta}\right) \\
\alpha_{6}=\eta_{x} \frac{\partial^{2} x}{\partial \eta^{2}}+\eta_{y} \frac{\partial^{2} y}{\partial \eta^{2}}
\end{gathered}
$$

ここで, $x, y$ および $t$ は直交座標系における平面および 時間軸である。

一般座標系における掃流砂の連続式は以下のものを 用いる:

$$
\frac{\partial}{\partial t}\left(\frac{z_{b}}{J}\right)+\frac{1}{1-\lambda}\left[\frac{\partial}{\partial \xi}\left(\frac{q^{\xi}}{J}\right)+\frac{\partial}{\partial \eta}\left(\frac{q^{\eta}}{J}\right)\right]=0
$$

ここで, $z_{b}$ は河床高, $\lambda$ は河床材料の空隙率, $q^{\xi}, q^{\eta}$ は $\xi, \eta$ 方向の単位幅掃流砂量で, $s$ 軸を水深平均流の流線 方向および $n$ 軸をこれに直交する方向とすると下記の 式で表される.

$$
\begin{gathered}
q^{\xi}=\frac{\partial \xi}{\partial s} q^{s}+\frac{\partial \xi}{\partial n} q^{n}= \\
\left(\xi_{x} \frac{\partial x}{\partial s}+\xi_{y} \frac{\partial y}{\partial s}\right) q^{s}+\left(\xi_{x} \frac{\partial x}{\partial n}+\xi_{y} \frac{\partial y}{\partial n}\right) q^{n} \\
q^{\eta}=\frac{\partial \eta}{\partial s} q^{s}+\frac{\partial \eta}{\partial n} q^{n}= \\
\left(\eta_{x} \frac{\partial x}{\partial s}+\eta_{y} \frac{\partial y}{\partial s}\right) q^{s}+\left(\eta_{x} \frac{\partial x}{\partial n}+\eta_{y} \frac{\partial y}{\partial n}\right) q^{n}
\end{gathered}
$$

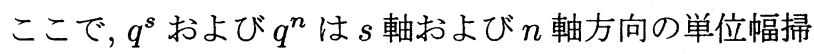
流砂量である. $q^{s}$ は長谷川ら ${ }^{7)}$ による次式を用いる.

$$
\begin{gathered}
q^{s}=\frac{17}{\cos \theta_{b}} \tau_{*}^{3 / 2}\left(1-\frac{\tau_{* c}}{\tau_{*}}\right)\left[1-\sqrt{\frac{2 \tau_{* c} \cos \theta_{b}}{\tau_{*}}}+\right. \\
\left.2\left(\tan \theta_{b}-\frac{\partial z_{b}}{\partial s}\right)\right] \sqrt{\left(\frac{\rho_{s}}{\rho}-1\right) d g^{3}}
\end{gathered}
$$

ここで, $\theta_{b}$ は流路平均勾配, $\rho_{s}$ は砂粒子の密度, $d$ は砂 粒子の直径, $\tau_{*}$ は無次元掃流力, $\tau_{* c}$ は無次元限界掃流 力で岩垣の式で求める. 式 (16) は芦田・道上の式 ${ }^{8)} に$ Kovacs \& Parker ${ }^{9)}$ の埋論を用いて重力㕮果の補正を加 えたものである.

$q^{n}$ は長谷川の式 ${ }^{10)}$ を用いて以下の式で表される.

$$
q^{n}=q^{s}\left(\frac{h}{r_{s}} N_{*}-\sqrt{\frac{2 \tau_{* c} \cos \theta_{b}}{\tau_{*}}} \frac{\partial z_{b}}{\partial n}\right)
$$

ここで, $r_{s}$ は水深平均流れの流線の曲率半径, $N_{*}$ は 2 次流強度を表す定数, $\mu_{s}, \mu_{k}$ はそれぞれ河床砂の静止お よび動摩擦係数である. $N_{*}$ は Engelund ${ }^{11)}$ による 7 を 用い, $\mu_{s}, \mu_{k}$ は標準的な值として 1.0 および 0.45 を用 いる. $r_{s}$ は Shimizu \& Itakura $\left.^{6}\right)$ による方法で求める.

$s$ 軸および $n$ 軸方向の河床勾配, $\partial z_{b} / \partial s$ and $\partial z_{b} / \partial n$ は以下の式で求める.

$$
\begin{gathered}
\frac{\partial z_{b}}{\partial s}=\frac{\partial z_{b}}{\partial \xi} \frac{\partial \xi}{\partial s}+\frac{\partial z_{b}}{\partial \eta} \frac{\partial \eta}{\partial s}= \\
\frac{\partial z_{b}}{\partial \xi}\left(\xi_{x} \frac{\partial x}{\partial s}+\xi_{y} \frac{\partial y}{\partial s}\right)+\frac{\partial z_{b}}{\partial \eta}\left(\eta_{x} \frac{\partial x}{\partial s}+\eta_{y} \frac{\partial y}{\partial s}\right)
\end{gathered}
$$


unit: $\mathrm{mm}$

$-1 \mathrm{~m} / \mathrm{s}$

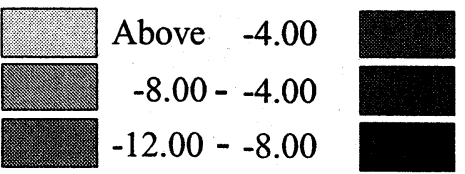

$-16.00--12.00$

$-20.00--16.00$

Below -20.00

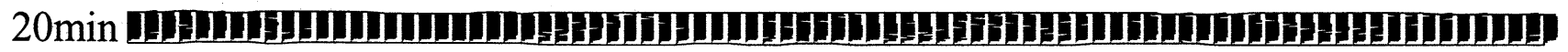

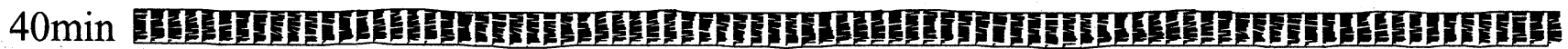

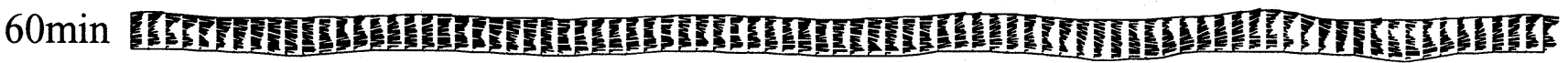

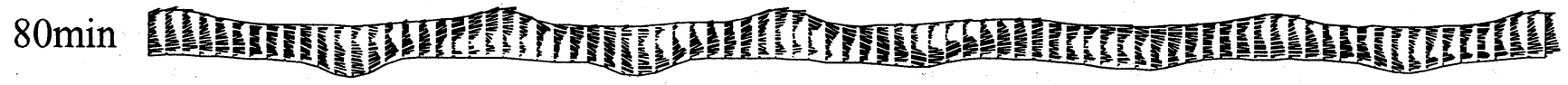

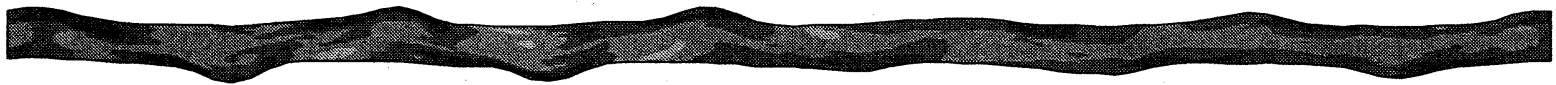

100min II

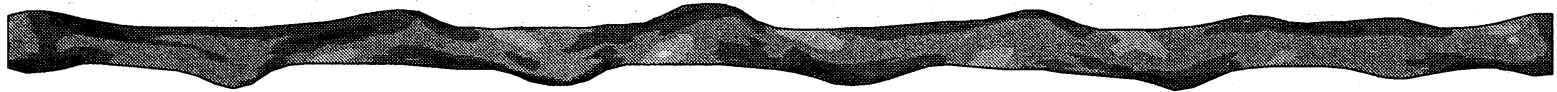

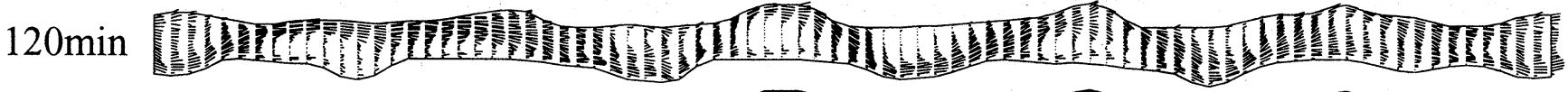

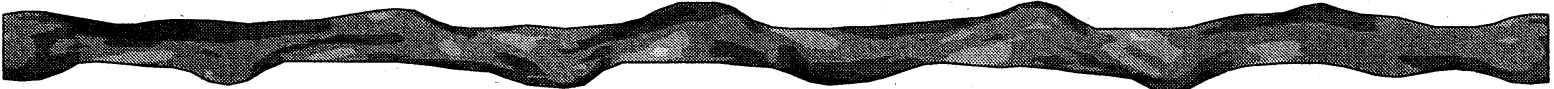

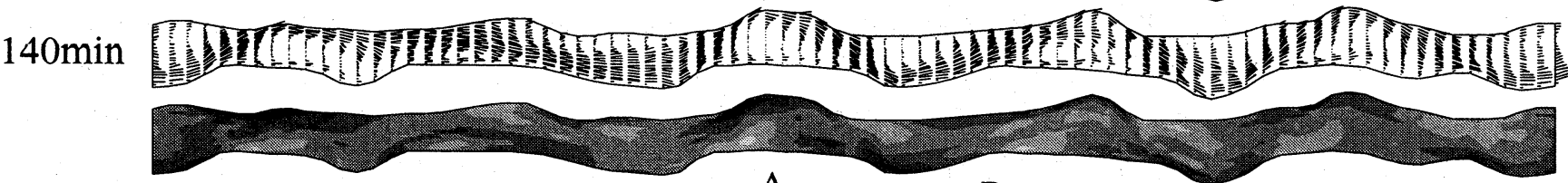

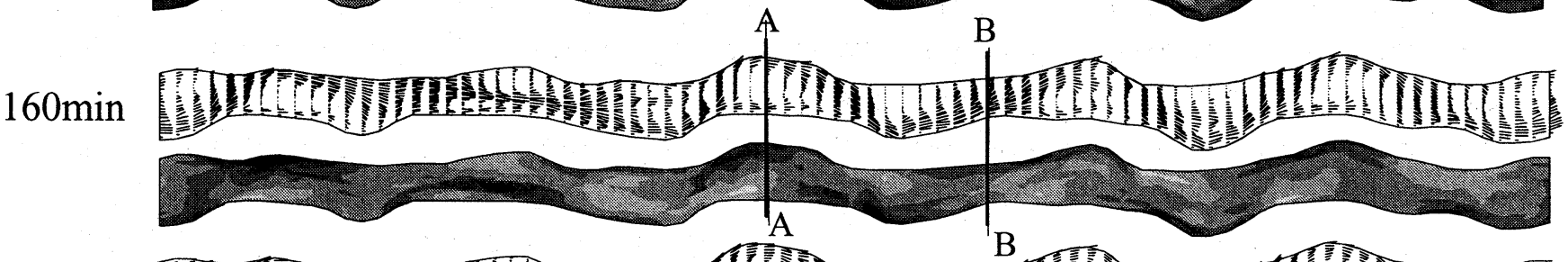

180min [intrim

図-2 計算結果河床コンター図および流速ベクトル図 


\section{表- 1 RUN B1.5-20 の実験条件}

\begin{tabular}{|l|l|l|}
\hline 河床材料粒径 & $d$ & $1.3 \mathrm{~mm}$ \\
\hline 初期河床勾配 & $S$ & $1.5 \%$ \\
\hline 流量 & $Q$ & $0.333 \times 10^{-3} \mathrm{~m}^{3} / \mathrm{s}$ \\
\hline 流砂量 & $Q_{s}$ & $0.583 \mathrm{~g} / \mathrm{s}$ \\
\hline
\end{tabular}

$$
\frac{\partial z_{b}}{\partial n}=\frac{\partial z_{b}}{\partial \xi} \frac{\partial \xi}{\partial n}+\frac{\partial z_{b}}{\partial \eta} \frac{\partial \eta}{\partial n}=
$$

$$
\frac{\partial z_{b}}{\partial \xi}\left(\xi_{x} \frac{\partial x}{\partial n}+\xi_{y} \frac{\partial y}{\partial n}\right)+\frac{\partial z_{b}}{\partial \eta}\left(\eta_{x} \frac{\partial x}{\partial n}+\eta_{y} \frac{\partial y}{\partial n}\right)
$$

無次元掃流力 $\tau_{*}$ は次式で計算される.

$$
\tau_{*}=\frac{C_{d}\left(u^{2}+v^{2}\right)}{\left(\rho_{s} / \rho-1\right) g d}
$$

ここで, $u, v$ は直交座標上の $x, y$ 方向の平均流速成分 である.

\section{3. 河岸侵食と河道平面形状の計算法}

初めに $\xi$ 座標軸を与えられた初期河道の流下方向, $\eta$ 座 標軸を横断方向にとり, $\xi$ 軸および $\eta$ 軸方向に適当に分 割することにより初期計算格子を配置する．前述の諸 式で流れと河床変動の計算を行いもし, 河岸近傍で河床 低下が生じ，河岸の角度が限界角 $\left(\theta_{c}\right)$ 以上になった場 合は図-1に示すように，限界角度を超える部分は瞬間 的に崩落するものと仮定し，その侵食量に等しい量の体 積の土砂量を河岸近傍の洗掘部分に埋め戻すこととす る. 同時に河岸侵食が生じた分だけ計算領域を拡大す る. また, 河床変動計算の過程で河岸近傍が陸地化した 場合は，その部分を計算領域から除外する.このように して左右岸の計算領域の拡大・縮小を計算した後にこ れを新たな境界として計算格子の再配置を行う.

流れおよび河床変動の計算式のうち移流項は CIP 法 で計算し,その他の空間微分項は中央差分で, 時間微分 項は前進差分で計算し, 与えられた初期条件から所定の 時間まで計算を継続する。 なお，上下流は周期境界条件 を用いることとする.

\section{4. 計算モデルの検証}

モデルによる計算結果を Bertoldi ${ }^{5)}$ らによる実験 (RUN B1.5-20) と比較を行うことにより，その有効性 を検証する. 実験は底面幅 $6 \mathrm{~cm}$, 河岸勾配 $40^{\circ}$ の台形断 面の直線水路で, 表-1 の条件で通水が行われ，実験開始 後 70 分, 130 分, 150 分で河床形状の測定が行われてい る. 実験と同じ条件で行われた計算結果の流速べクト ルと河床コンターを図 -2 に示す $\left(\tan \theta_{c}=0.6\right.$ とした $)$.

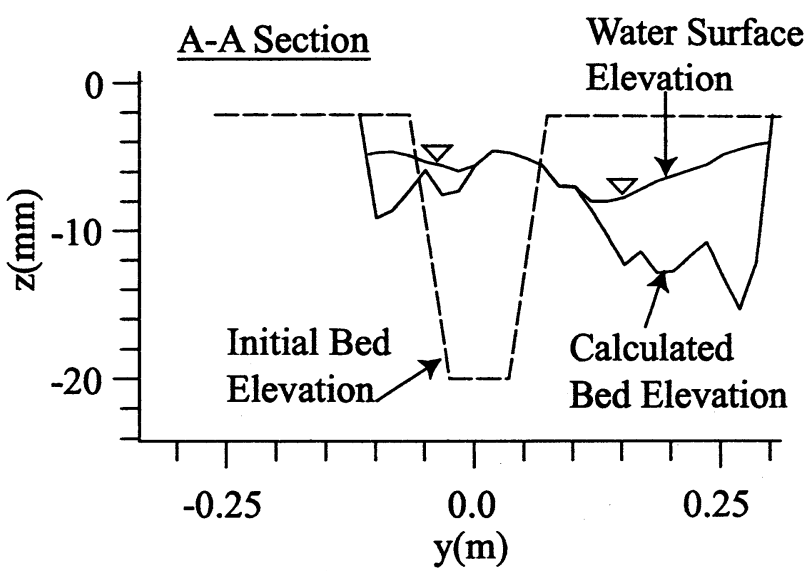

図- 3 A-A 断面における河床および水面形状の計算 結果

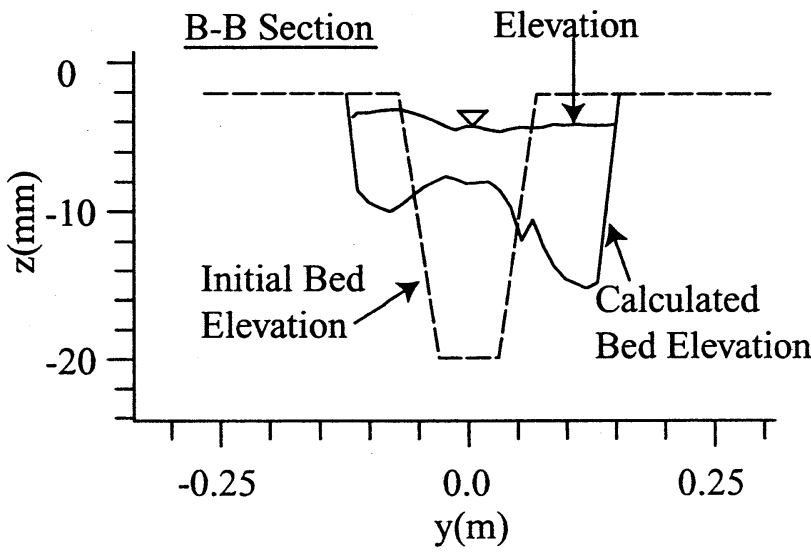

図-4 B-B 断面における河床および水面形状の計算結果

はじめに交互砂州が形成され，時間と共に左右岸交互の 河岸侵食と水路幅の拡幅が計算されている. 計算開始 後 160 分における A-A および B-B 断面の形状を図-3, 4に示す. 図-3 では中洲が形成され, 流路の分岐が計算 されている. 図-5 は 70, 130, 150 分における実験結果 と計算結果の河床コンター図の比較である.ここで, 実 験結果のほうは河岸上部（実際には水の無い部分）ま でのプロットであるが計算結果は左右岸の計算境界か ら流路中央に向かって最初に水際線が現れた地点を水 際線としてこの水際線の範囲のプロットであるため水 際付近の形状が異なるが, 河床形状や流路の平面形状 はある程度再現されているようである，ただし，詳細 に見ると侵食の位置やその程度が微妙に異なっており， 流路形状も位相差が見られる. 計算結果は $\theta_{c}$ の与え方 によって非常に敏感に異なるため, より検討の余地が あると考えられる。

\section{5. 河岸の耐侵食強度に関する考察}

本モデルでは, 河岸の耐侵食強度は河岸の限界勾配 $\theta_{c}$ で表される. そこで, $\theta_{c}$ の違いによる平面変動特性の違 いに関して考察を行う. 図-6 は $\tan \theta_{c}$ を $0.5 \sim 1.7$ の範 囲で, 同様の計算を行った結果である. ここで, $\tan \theta_{c}$ の 

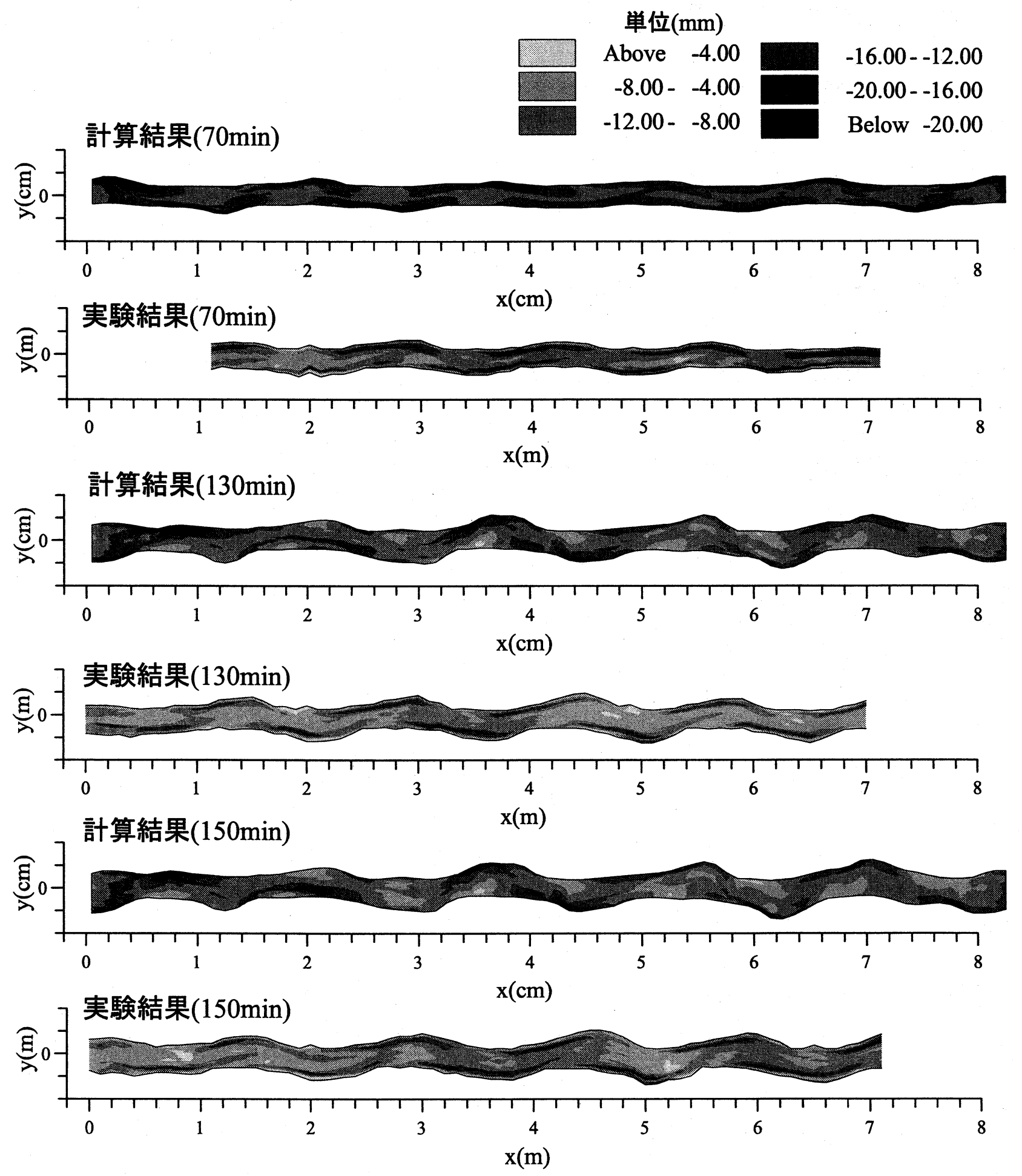

図- 5 河床コンター図および流速ベクトルの計算と実験の比較 


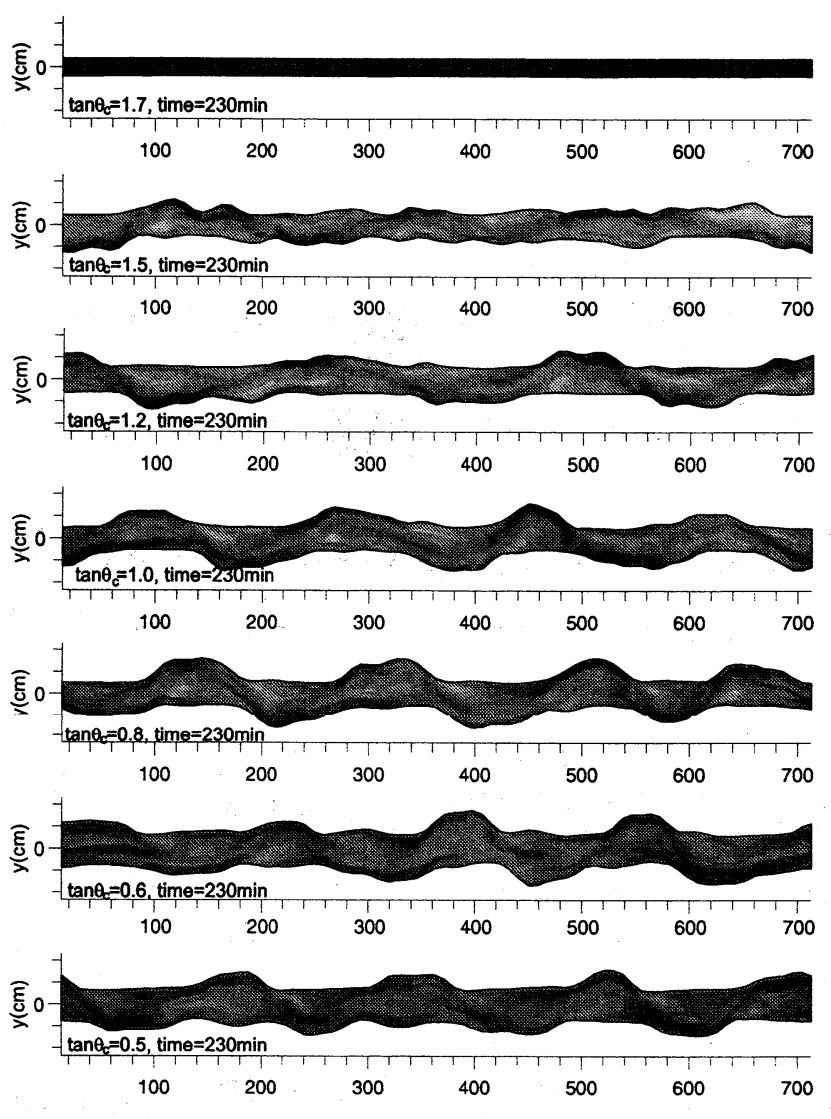

\section{図一 6 河岸の耐侵食強度の違いによる河道平面形状の 比較}
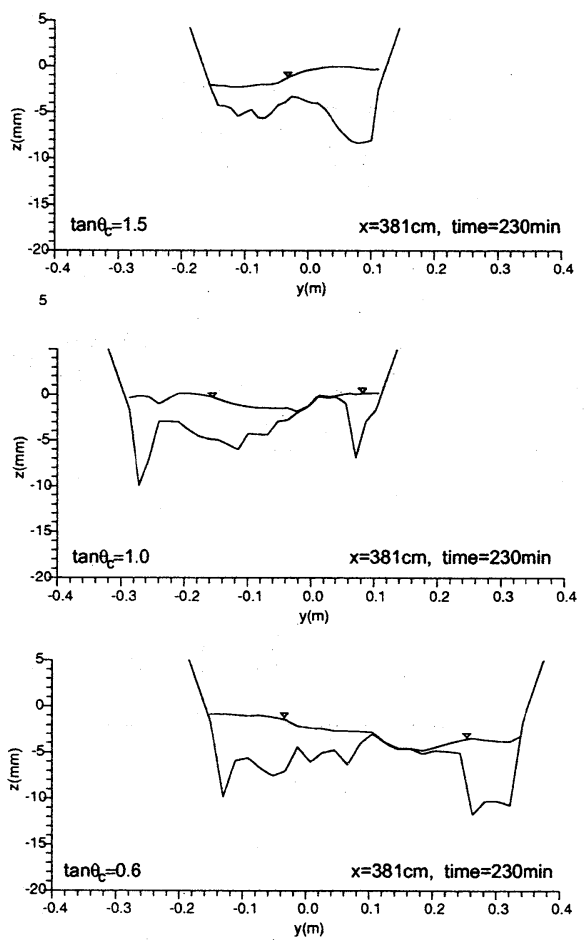

図- 7 河岸の耐侵食強度の違いによる河道横断形状の 比較
值が大きいほど河岸の耐侵食強度が強く(例えば粘性河 岸や植生の根が密集した河岸) で, 小さいほど河岸の耐 侵食強度が弱い(例えば砂質河岸) と見なせる. なお,こ こでの $\theta_{c}$ は物意的な意味での安息角ではなく河岸の耐 侵食強度を便宜的に表したものである. 図-6によれば， $\theta_{c}$ が大きい場合には, 河道は蛇行せず, $\theta_{c}$ が大きくなる につれて河岸侵食の波長, 振幅も大きくなるような傾 向も見られるが，あまり明瞭とは言えない．河岸の幾何 学形状は河床の砂州の形状と相互依存していると思わ る. 即ち, 初期条件においては非砂州の条件であるが河 幅の拡幅に伴い交互砂州が形成され，この交互砂州の移 動速度と河岸侵食速度のバランスにより砂州が完全に トラップされる場合と, 一旦トラップされかけるがまた 移動して別の場所が侵食される場合なじ複雑な相互関 係により平面地形が形成されているようである. 図-7 は図-6 の $\mathrm{x}=381 \mathrm{~cm}$ 地点における $\tan \theta_{c}=0.6,1.0,1.5$ の場合の断面形状を示したものである. 限界角度が大き い場合には河道の拡幅は制限され, 大きい場合には全体 的に拡幅し，その中間の場合には中洲が形成されている.

\section{参考文献}

1) 長田信寿, 細田尚, 村本嘉雄, M.,Rahman : 移動一般座標 系による側岸浸食を伴う河道変動の数值解析, 水工学論文集 第 40 巻, pp.927-932, 1996

2) 長田信寿, 細田尚, 村本嘉雄, M.,Rahman : 河岸侵食過程 における流砂の非平衡性を考慮した流路変動の数值解析, 水 工学論文集第 41 巻, pp.889-894, 1997.

3) 清水康行, 平野道夫, 渡邊康玄: 河岸浸食と自由蛇行の数值 計算, 水工学論文集第 41 巻, pp.921-926, 1996.

4) Yabe, T., Ishikawa, T.: A Numerical Cubic-Interpolated Pseudoparticle(CIP) Method without Time Splitting Technique for Hyperbokic Equations, Journal of the Physical Society of Japan, Col.59, No.7, pp.2301-2304, 1990.

5) Bertoldi, W., Tubino, M. and Zolezzi: Laboratory measurements on channel bifurcation. Proc. of 2nd IAHR Symposium on River Coastal and Estuarine Morphodynamics, pp.723-732., 2001.

6) Shimizu, Y. and Itakura, T.: Calculation of flow and bed deformation with a general non-orthogonal coordinate system, Proc. of XXIV IAHR Cong. Madrid, Spain, Vol. C, 241-248., 1991.

7) 長谷川和義, 藤田豊彦, 目黒嗣樹, 竜澤宏昌: 河床不安定 および分級不安定をともなう急勾配混合砂磁河床の形態: 水 工学論文集第 44 巻, pp.659-664, 2000.

8) 芦田和男, 道上正規: 移動床流れの抵抗と掃流砂量に関す る基礎的研究, 土木学会論文集, 第 206 号, pp.59-69, 1972.

9) Kovacs, A. and Parker, G.: A new vectorial bedload formulation and its application to the time evolution of straight river channels. Jour. of Fluid Mrch., 267, 153183., 1994.

10）長谷川和義: 沖積蛇行の平面および河床形状と流れに関 する水理学的研究, 北海道大学学位論文, 1983.

11) Engelund, F.: Flow and bed topography in channel bends. J. Hyd. Div., ASCE, 100(11), 1631-1648., 1974.

(2002. 9. 30受付) 